\title{
Impairment in psychosocial functioning in patients with different subtypes of eating disorders
}

\author{
O prejuízo no funcionamento psicossocial de pacientes \\ com diferentes subtipos de transtorno alimentar
}

\author{
Carolina Meira Moser, ${ }^{1}$ Maria Inês Rodrigues Lobato, ${ }^{2}$ Adriane R. Rosa, ${ }^{3}$ Emi Thomé, ${ }^{1}$ Julia Ribar, ${ }^{1}$ Lucas Primo, ${ }^{1}$ \\ Ana Carolina Faedrich dos Santos, ${ }^{1}$ Miriam Garcia Brunstein ${ }^{1}$
}

\begin{abstract}
Objective: To examine psychosocial functioning in eating disorder (ED) patients with restrictive and purgative subtypes.

Method: Forty-four adult female patients with a diagnosis of ED were divided into restrictive (RP) and purgative (PP) groups according the presence of purgative symptoms. Functioning was assessed using the Functioning Assessment Short Test (FAST) and the Global Assessment of Functioning Scale (GAF).

Results: No differences were found in total FAST scores or in specific domains between the RP $(39.58 \pm 11.92)$ and PP $(45.75 \pm 11.75)$ groups $(p=0.19)$. However, PP showed more severe functional impairment than RP in the financial domain ( $p$ $<0.01$ ). There were no differences in comorbidity with mood disorders, depressive symptoms, or general psychiatric symptoms between the two ED subtypes.

Conclusions: The similarities found between PP and PR in overall functioning and in autonomy, cognition, work, interpersonal relationships, and leisure seem to reflect the use of an objective scale that corresponds to the clinical impression. In fact, the assessment of psychosocial functioning in ED patients using self-report instruments requires careful consideration because results may reflect the egosyntonic nature of symptoms commonly observed in these patients, particularly in the restrictive subtype. Keywords: Eating disorders, anorexia nervosa, bulimia nervosa, psychosocial factors.
\end{abstract}

\begin{abstract}
Resumo
Objetivo: Avaliar o funcionamento psicossocial de pacientes com subtipos restritivo e purgativo de transtorno alimentar (TA). Métodos: Quarenta e quatro pacientes adultas com TA foram divididas em grupos restritivo (RP) e purgativo (PP) conforme a presença de sintomas purgativos. O funcionamento foi avaliado com a Functioning Assessment Short Test (FAST) e a Global Assessment of Functioning Scale (GAF).

Resultados: Não houve diferenças nos escores totais nem nos domínios da FAST entre os grupos RP $(39,58 \pm 11,92)$ e PP $(45,75 \pm 11,75)(p=0,19)$. No entanto, o grupo PP demonstrou maior prejuízo funcional no domínio finanças $(p<0,01)$. RP e PP foram semelhantes em comorbidade com transtornos de humor, sintomas depressivos e sintomas psiquiátricos em geral.

Conclusões: As semelhanças encontradas entre os grupos PP e RP no funcionamento geral e nos domínios autonomia, cognição, trabalho, relacionamentos interpessoais e lazer parecem refletir o uso de uma escala objetiva que corresponde à impressão clínica. De fato, é necessário cautela ao avaliar funcionamento psicossocial em pacientes com TA com escalas autoaplicáveis, porque estas costumam refletir a natureza egossintônica dos sintomas comumente observados nesses pacientes, especialmente no subtipo restritivo.
\end{abstract}

Descritores: Transtornos alimentares, anorexia nervosa, bulimia nervosa, fatores psicossociais.

\footnotetext{
${ }^{1}$ Adult Eating Disorders Program, Hospital de Clínicas de Porto Alegre (HCPA), Porto Alegre, RS, Brazil. Universidade Federal do Rio Grande do Sul (UFRGS), Porto Alegre, RS, Brazil. ${ }^{2}$ HCPA and UFRGS, Porto Alegre, RS, Brazil. ${ }^{3}$ Bipolar Disorders Program, Clinical Institute of Neuroscience, Hospital Clinic of Barcelona, Barcelona, Spain.

This article is part of the master's thesis entitled Functioning in adult patients with eating disorders (Avaliação da funcionalidade em pacientes adultos com transtornos alimentares), presented in 2011 at Universidade Federal do Rio Grande do Sul (UFRGS), Porto Alegre, RS, Brazil.

Partial results of this article were presented at the Rio International Eating Disorders and Obesity Conference, 19-20 November, 2010.

Financial support: This research was supported by Fundo de Incentivo à Pesquisa - Hospital de Clínicas de Porto Alegre (FIPE-HCPA), Conselho Nacional de Desenvolvimento Científico e Tecnológico (CNPq), and Coordenação de Aperfeiçoamento de Pessoal de Nível Superior (CAPES) (GPPG/HCPA protocol no. 08-065), and has received the Cyro Martins Research Incentive Award from Associação de Psiquiatria do Rio Grande do Sul (APRS).

Submitted Apr 06 2012, accepted for publication Aug 19 2012. No conflicts of interest declared concerning the publication of this article.

Suggested citation: Moser CM, Lobato MI, Rosa AR, Thomé E, Ribar J, Primo L, dos Santos AC, et al. Impairment in psychosocial functioning in patients with different subtypes of eating disorders. Trends Psychiatry Psychother. 2013;35(2):111-8.
} 


\section{Introduction}

Treatment outcome measurement in eating disorders (ED) has traditionally focused on changing behavior and improving symptoms. Patients are assessed for outcomes such as a reduction in purging behavior or the achievement of a healthy body weight rather than broader areas such as role functioning or quality of life (QoL). ${ }^{1}$ The impact of EDs, including partial forms, on broader life functioning is well documented ${ }^{2-9}$ and comparable to that of anxiety disorders, ${ }^{4}$ affective disorders, ${ }^{4}$ and schizophrenia. ${ }^{9}$ Moreover, poor psychosocial functioning has been linked to premature death in ED. ${ }^{10-12}$

Among ED behaviors, the use of extreme weightcontrol methods, particularly self-induced vomiting, has been associated with the highest levels of impairment. ${ }^{4}$ Patients with the restrictive type of anorexia nervosa typically report an inflated QoL early in treatment, similar to what is observed with healthy controls. ${ }^{13}$ This observation would suggest that non-purging patients may have better functioning than those who purge. However, there is also objective evidence of adverse effects on health and functioning in restrictive forms of ED. Inflated QoL scores may be an artifact of the egosyntonic nature of symptoms in these patients, which are difficult to capture with self-report instruments. ${ }^{13-15}$

Most studies use generic instruments to assess health-related QoL in ED patients, such as the World Health Organization Brief Quality of Life Assessment Scale (WHOQoL-Bref) ${ }^{16}$ and the Medical Outcomes Short Form-SF Health Survey 36 (SF-36). ${ }^{17}$ Although valuable, these measures were originally developed to assess the impact of physical illnesses on everyday functioning, and may therefore miss important aspects of psychopathology specific to psychiatric diagnoses such as ED. To avoid these limitations, an instrument - the Clinical Impairment Assessment - has been developed to specifically assess the personal, cognitive, and social impact of ED; however, this is a self-report questionnaire, and thus subject to the limitations already mentioned. ${ }^{2}$

In this scenario, functioning could be a more suitable and consistent construct to measure the impact of psychopathology in ED. Assessing the impact of psychiatric disorders is important for at least two reasons: first, impairment leads people to seek help, and therefore a goal of treatment should be to reduce impairment ${ }^{18}$; second, the presence of clinically significant impairment is required for a diagnosis of mental disorder. ${ }^{19}$ However, the concept of functioning is complex and involves many different domains, including the ability to work, live independently, engage in recreation, experience romantic life, and study effectively. ${ }^{20}$ These aspects have been recently integrated in a new and easily administered scale, the Functioning Assessment Short Test (FAST), which fulfills the need for an assessment of multiple domains of psychosocial functioning in mental disorders. The FAST comprises 24 items and allows for the evaluation of six specific areas of functioning: autonomy, occupational functioning, cognitive functioning, financial issues, interpersonal relationships, and leisure time.

Considering that the aforementioned items were identified as the main problems experienced by mentally ill patients, and taking into account the performance and psychometric proprieties of the FAST instrument in subjects with bipolar disorder, ${ }^{20}$ the aim of the present study was to examine psychosocial functioning in patients with different subtypes of ED using the FAST. Our hypothesis was that this scale could identify impairments in multiple domains of functioning in this population and reveal possible differences between the restrictive and purgative subtypes of ED.

\section{Methods}

\section{Design and participants}

A sample of female out- and inpatients with a diagnosis of anorexia nervosa, bulimia nervosa, or partial syndromes of anorexia nervosa or bulimia nervosa referred to the Adult Eating Disorders Program of Hospital de Clínicas de Porto Alegre (HCPA) and a group of healthy controls were recruited from August 2008 to August 2011.

Patients with the purgative subtype of anorexia nervosa, partial purgative ED syndrome, and bulimia nervosa formed the group of purgative patients (PP). Patients with the restrictive subtype of anorexia nervosa and partial restrictive ED syndromes composed the group of restrictive patients (RP). Healthy women formed the control group (C).

Psychiatric diagnoses were established according to criteria from the Diagnostic and Statistical Manual of Mental Disorders, 4th edition, Text Revision (DSM-IV-TR). A semistructured interview based on the Mini-International Neuropsychiatric Interview (MINI) - validated for use in Brazilian populations - was applied by a psychiatrist to investigate psychiatric disorders according to DSM-IV TR criteria. ${ }^{21}$ Patients presenting neurodegenerative disorders, psychotic symptoms, or mental retardation were excluded. Healthy women were recruited among workers and students at HCPA and Universidade Federal do Rio Grande do Sul (UFRGS). Control subjects were screened to rule out history of ED or other psychiatric conditions.

All participants were informed about the study goals and were asked to sign an informed consent 
form. All procedures were conducted in agreement with the Brazilian National Health Council (Resolution no. 196/1996) and with the Declaration of Helsinki. The study protocol was approved by the Research Ethics Committee of the institution.

\section{Instruments}

\section{Clinical and sociodemographic assessment}

Clinical assessment included the following scales of ED psychopathology: the Eating Attitudes Test (EAT26), ${ }^{22,23}$ for evaluating eating habits and dietary practices; the Body Shape Questionnaire (BSQ), 24,25 for assessing body satisfaction; and the Bulimic Investigatory Test of Edinburgh (BITE), ${ }^{26,27}$ for evaluating purgative behavior and binge eating. EAT-2623 and BITE ${ }^{26}$ have been validated to Portuguese, and the $\mathrm{BSQ}^{25}$ has been translated into Portuguese. In addition, the Symptom Checklist-90 (SCL-90) ${ }^{28,29}$ was used to evaluate general psychological distress, the 17-item Hamilton Depression Rating Scale (HDRS-17) ${ }^{30}$ for depressive symptoms, and a questionnaire specifically designed to collect sociodemographic information. Although broadly used in Brazilian studies, instruments SCL-90 and HDRS-17 have not effectively validated for use in Brazilian Portuguese. Height and weight were measured as part of the intake assessment and enabled calculation of the body mass index (BMI; kg/m²).

EAT, BITE, BSQ, and SCL-90 are self-report scales. The FAST and HDRS-17 instruments are intervieweradministered.

\section{Functioning assessment}

Impairment in role functioning was assessed using the FAST ${ }^{20}$ and the Global Assessment of Functioning Scale (GAF). ${ }^{31}$

The FAST (Figure 1) is an interviewer-administered questionnaire designed to evaluate overall function

\begin{tabular}{|c|c|c|c|c|}
\hline $\begin{array}{l}\text { ESCALA BREVE DE FUNC } \\
\text { Por favor, pergunte ao paciente as frases abaixo e resp } \\
\text { Para responder utilize a seguinte escala: }(\mathbf{0}): \text { nenh }\end{array}$ & $\begin{array}{l}\text { grau } \\
\text { te ou }\end{array}$ & $\begin{array}{l}\text { e dificu } \\
\text { ): mui }\end{array}$ & $\begin{array}{l}\text { dade. } \\
\text { a. }\end{array}$ & \\
\hline AUTONOMIA & & & & \\
\hline 1. Ser responsável pelas tarefas de casa & ( 0 ) & (1) & ( 2 ) & ( 3 ) \\
\hline 2. Morar sozinho & (0) & (1) & (2) & (3) \\
\hline 3. Fazer as compras de casa & ( 0 ) & ( 1 ) & ( 2 ) & ( 3 ) \\
\hline 4. Cuidar-se de si mesmo (aspecto físico, higiene) & ( 0$)$ & (1) & ( 2 ) & ( 3 ) \\
\hline TRABALHO & & & & \\
\hline 5. Realizar um trabalho remunerado & ( 0 ) & (1) & ( 2 ) & ( 3 ) \\
\hline 6. Terminar as tarefas tão rápido quanto era necessário & (0) & (1) & ( 2 ) & ( 3 ) \\
\hline 7. Obter o rendimento previsto no trabalho & ( 0 ) & (1) & ( 2 ) & ( 3 ) \\
\hline 8. Trabalhar de acordo com seu nível de escolaridade & (0) & (1) & (2) & (3) \\
\hline 9. Ser remunerado de acordo com o cargo que ocupa & ( 0 ) & (1) & ( 2 ) & ( 3 ) \\
\hline COGNIÇÃO & & & & \\
\hline 10. Concentrar-se em uma leitura, um filme & ( 0 ) & (1) & ( 2 ) & ( 3 ) \\
\hline 11. Fazer cálculos mentais & (0) & (1) & ( 2 ) & ( 3 ) \\
\hline 12. Resolver adequadamente os problemas & ( 0 ) & (1) & ( 2 ) & ( 3 ) \\
\hline 13. Lembrar o nome de pessoas novas & (0) & (1) & (2) & (3) \\
\hline 14. Aprender uma nova informação & ( 0 ) & (1) & ( 2 ) & ( 3 ) \\
\hline FINANÇAS & & & & \\
\hline 15. Administrar seu próprio dinheiro & ( 0 ) & ( 1 ) & ( 2 ) & ( 3 ) \\
\hline 16. Fazer compras equilibradas & (0) & (1) & (2) & (3) \\
\hline RELAÇÕES INTERPESSOAIS & & & & \\
\hline 17. Manter uma amizade & ( 0 ) & ( 1 ) & ( 2 ) & ( 3 ) \\
\hline 18. Participar de atividades sociais & ( 0 ) & (1) & ( 2 ) & ( 3 ) \\
\hline 19. Dar-se bem com pessoas a sua volta & ( 0 ) & (1) & ( 2 ) & ( 3 ) \\
\hline 20. Convivência familiar & ( 0$)$ & (1) & ( 2 ) & ( 3 ) \\
\hline 21. Relações sexuais satisfatórias & ( 0 ) & ( 1 ) & ( 2 ) & ( 3 ) \\
\hline 22. Capaz de defender os próprios interesses & (0) & (1) & ( 2 ) & ( 3 ) \\
\hline LAZER & & & & \\
\hline 23. Praticar esporte ou exercícios & (0) & (1) & ( 2 ) & ( 3 ) \\
\hline 24. Ter atividades de lazer & ( 0 ) & (1) & ( 2 ) & ( 3 ) \\
\hline
\end{tabular}

Figure 1 - Functioning Assessment Short Test (FAST) in Brazilian Portuguese 
across multiple domains in psychiatric patients. The FAST was shown to be a reliable and valid measure in patients with bipolar disorder ${ }^{20,32}$ and subjects experiencing a first psychotic episode. ${ }^{33}$ The FAST scale consists of 24 items covering six specific areas of functioning, as follows: 1) autonomy (patient's ability to do things alone and make individual decisions); 2) occupational functioning (ability to maintain a paid job, efficiency in performing tasks at work, working in the field in which the patient was educated, and earning according to the level of the position); 3) cognitive functioning (ability to concentrate, perform simple mental calculations, solve problems, learn new information, and remember learned information); 4) financial issues (ability to manage finances and spending in a balanced way); 5) interpersonal relationships (relations with friends, family, involvement in social activities, sexual relations, and the ability to defend ideas and opinions); and 6) leisure time (ability to perform physical activities and to enjoy hobbies).

The FAST was developed by the Bipolar Disorder Program of the University of Barcelona Hospital Clinic. Items are rated using a 4-point scale ranging from 0 (no difficulty) to 3 (severe difficulty), with a total score ranging between 0 and 72 (higher scores indicate poorer functioning). The original authors suggested a cut-off point of $\geq 11$ in Spanish subjects with bipolar disorder as a measure of disability, as it improved the discriminant properties of the test to a sensitivity of $72 \%$ and a specificity of $87 \% .{ }^{20}$ One hundred outpatients with bipolar disorder and one hundred controls were recruited for the FAST validation study in Brazil. ${ }^{32}$ That study showed high internal consistency (Cronbach's alpha was 0.95 for the whole scale and 0.82 or higher for the subscales). Test-retest reliability for total FAST scores was excellent $(r=0.90 ; p<0.001)$. Concurrent validity was based on functional impairment according to the GAF scale, which assesses only overall functioning (higher scores on the GAF suggest better functioning). ${ }^{32}$ Total FAST scores were strongly correlated with GAF scores (rho $=-0.70, p<0.001)$. The FAST scale is available in several languages, including Portuguese, as used in our sample. A single interviewer (C.M.M.), a psychiatrist with 8 years of training and clinically experienced with scales, examined all patients and controls.

\section{Statistical analysis}

The Shapiro-Wilk test was used to investigate data distribution in the sample. Symmetric variables were expressed as means and standard deviation (SD). Asymmetric variables were expressed as medians and interquartile range (Q1-Q3). For asymmetric variables, data were transformed using a logarithmic function to allow the use of parametric tests and thus modify the distribution of variables.

Sociodemographic and clinical variables (comorbidities) were evaluated using descriptive statistics (frequency and percentage).

Age, BMI, scores obtained in EAT, BSQ, BITE, SCL90, FAST total, all FAST domains, and GAF variables were compared across the PP, RP, and $C$ groups using the Kruskal-Wallis test. Age at onset of ED was analyzed using Mann-Whitney's test, and HDRS-17 scores were compared between PP and RP using a $t$ test. Total FAST scores were analyzed using one-way analysis of variance (ANOVA).

Demographic data and comorbidity with psychiatric disorders were analyzed using the chi-square test and Fisher's exact test. Internal consistency of FAST scores was analyzed using Cronbach's alpha. The correlation between FAST and GAF scores was calculated using Spearman's correlation coefficient.

All analyses were performed using the Statistical Package for the Social Sciences (SPSS), version 18.0. Statistical significance was set at $p<0.05$ (95\% power).

\section{Results}

A total of 44 ED patients were recruited, namely, 12 RP (eight with restrictive anorexia nervosa and four with a partial syndrome of restrictive anorexia nervosa) and 32 PP (10 with purgative anorexia nervosa, 19 with bulimia nervosa, and three with partial purgative syndromes). The control group included 37 healthy women.

As shown in Table 1, there were no significant age differences across the three groups. The sample comprised $90.6 \%$ of outpatients in the PP group and $58.3 \%$ of inpatients in the RP group. The majority of ED patients (RP and PP groups) had completed high school. Most RP were single, and $43.8 \%$ of PP had a partner. Ninety-eight percent of the total sample was Caucasian.

As expected, BMI was significantly lower in the RP group when compared with the other two groups $(p<0.01)$. The two groups of patients did not show significant differences in terms of age at onset, age at diagnosis, or HDRS-17 scores. EAT and SCL-90 scores were significantly lower in controls $(p<0.01)$, but similar between the PP and RP groups. BITE and BSQ scores were significantly higher in the PP group when compared with the RP and C groups ( $p<0.01$ ) (Table 1$)$.

The internal consistency coefficient obtained for FAST in our sample was high, with a Cronbach's alpha of 0.892 for the total scale, indicating that the items were sufficiently homogeneous for this population. A strong 
Table 1 - Demographic and clinical characteristics of subjects

\begin{tabular}{|c|c|c|c|c|}
\hline Variable & $P P(n=32)$ & $R P(n=12)$ & $C(n=37)$ & $\mathbf{p}$ \\
\hline $\mathrm{Age}^{*+}$ & $30(21.5-44.75)$ & $30(21.25-44)$ & $24(20.5-31)$ & 0.09 \\
\hline \multicolumn{5}{|l|}{ Education ${ }^{\ddagger}$} \\
\hline Incomplete elementary school & $4(12.5 \%)$ & $1(0.83 \%)$ & $0(0 \%)$ & 0.001 \\
\hline Complete elementary school & $8(25 \%)$ & $1(0.83 \%)$ & $0(0 \%)$ & \\
\hline Complete high school & $18(56.3 \%)$ & $8(67.7 \%)$ & $22(59.5 \%)$ & \\
\hline Complete college & $2(6.3 \%)$ & $2(16.7 \%)$ & $15(40.5 \%)$ & \\
\hline \multicolumn{5}{|l|}{ Household income ${ }^{\ddagger \S}$} \\
\hline$<$ US\$ 320 & $6(18.8 \%)$ & $3(25 \%)$ & $0(0 \%)$ & 0.001 \\
\hline US\$321-1600 & $24(75 \%)$ & $7(58.3 \%)$ & $3(8.1 \%)$ & \\
\hline > US\$1601 & $2(6.3 \%)$ & $2(16.7 \%)$ & $34(91.9 \%)$ & \\
\hline \multicolumn{5}{|l|}{ Marital status ${ }^{\ddagger}$} \\
\hline Single & $18(56.3 \%)$ & $9(75 \%)$ & $30(81.1 \%)$ & 0.074 \\
\hline With partner & $14(43.8 \%)$ & $3(25 \%)$ & $7(18.9)$ & \\
\hline BMI $\left(\mathrm{kg} / \mathrm{m}^{2}\right)^{*+}$ & $22.09(19.6-27.31)$ & $17.90(16.29-19.58)$ & $20.82(20.12-22.15)$ & $\mathrm{PP}, \mathrm{C}>\mathrm{RP}$ \\
\hline Age at onset*\|l & $15.5(14-22)$ & $18.5(13.75-31.5)$ & & 0.36 \\
\hline Age at diagnosis ${ }^{\text {III }}$ & $27.84(12.19)$ & $28.08(10.49)$ & & 0.37 \\
\hline \multicolumn{5}{|l|}{ Rating scales* } \\
\hline EAT- $26^{+}$ & $35(26-39)$ & $12.25(4.25-31.5)$ & $5(3-10)$ & $\mathrm{PP}, \mathrm{RP}>\mathrm{C}$ \\
\hline BITE $^{+}$ & $21.5(14.25-25)$ & $7(5-16)$ & $4(2-8)$ & $\mathrm{PP}>\mathrm{RP}, \mathrm{C}$ \\
\hline $\mathrm{BSQ}^{+}$ & $161.5(115.75-186)$ & $62(45.5-151.5)$ & $61(49-80)$ & $\mathrm{PP}>\mathrm{RP}, \mathrm{C}$ \\
\hline SCL- $90^{+}$ & $185(134-214.4)$ & $111(46.25-206.25)$ & $20(7.5-36.5)$ & $\mathrm{PP}, \mathrm{RP}>\mathrm{C}$ \\
\hline HDRS-17II & $16.63(7.05)$ & $16.42(8.07)$ & & 0.83 \\
\hline
\end{tabular}

Data expressed as absolute frequency (percentage), * median (interquartile range: Q1-Q3), or ^ mean (standard deviation).

Data analyzed using ${ }^{+}$ANOVA, ${ }^{\neq}$the chi-square test, or "Student's t test.

$\S$ Exchange rate at the time of the study: US\$ $1.00=\mathrm{R} \$ 2.00$.

BITE = Bulimic Investigatory Test of Edinburgh; BMI = body mass index; BSQ = Body Shape Questionnaire; C = control group; EAT-26 = Eating Attitudes Test; ED = eating disorders; HDRS-17 = 17-item Hamilton Depression Rating Scale; PP = purgative patients; RP = restrictive patients; SCL-90 = Symptom Checklist-90; SD = standard deviation.

Table 2 - Scores obtained for FAST total, FAST domains, and GAF

\begin{tabular}{lcccc}
\hline Variable & PP & RP & C & Tukey* \\
\hline FAST autonomy & $6(3.25-7.75)$ & $6(3.25-8.75)$ & $1(0-2)$ & PP, RP $>$ C \\
FAST work & $14.5(9-15)$ & $15(5.25-15)$ & $1(0-2)$ & PP, RP $>$ C \\
FAST cognition & $10(6-13)$ & $6.5(4-10.75)$ & $1(1-5)$ & PP, RP > C \\
FAST finances & $5(3-6)$ & $1.5(0.25-2.75)$ & $1(0-2)$ & PP $>$ RP, C \\
FAST relationships & $10.5(8-13)$ & $11(5.25-16.5)$ & $1(0-3)$ & PP, RP $>$ C \\
FAST leisure & $4.5(2-6)$ & $2(2-3)$ & $1(0-2)$ & PP, RP $>$ C \\
FAST totalt & $45.75(11.75)$ & $39.58(16.76)$ & $8.66(5.18)$ & PP, RP $>$ C \\
GAF total & $40.5(31-45)$ & $44.5(32-57.25)$ & $95(90.5-100)$ & PP, RP $>$ C \\
\hline
\end{tabular}

Data expressed as median (interquartile range: Q1-Q3) or ${ }^{+}$mean (standard deviation).

$\mathrm{C}=$ control group; FAST = Functioning Assessment Short Test; GAF = Global Assessment of Functioning Scale; PP = purgative patients; RP = restrictive patients.

$* p<0.05$.

and significant correlation was also observed between FAST and GAF scores $(r=-0.89 ; p<0.01)$, i.e., patients with poor functioning obtained high scores on FAST and low ones on GAF.

No differences were found in total FAST scores between the RP and PP groups. However, PP scores were higher than RP ones in the financial domain ( $p<$ 0.01 ), revealing a more severe impairment in this area among PP (Table 2). As expected, mean FAST scores were significantly higher in ED patients than in healthy subjects in all domains (autonomy, work, cognition, finances, relationships, and leisure).

The prevalence of comorbidities in the RP and PP groups was high, as shown in Table 3. Only the PP group presented indications of alcohol and substance abuse. Moreover, the proportion of subjects with a history of suicide attempts was significantly higher in the PP group. Additionally, the PP group showed a statistical tendency toward having more phobias (agoraphobia, specific phobia, and social phobia) than the RP group. Other measures were not significantly different between the groups. 
Table 3 - Comorbidities in restrictive and purgative eating disorders (Fisher's exact test)

\begin{tabular}{lccc}
\hline & PP (n = 32) & RP (n = 12) & p \\
Major depression & \% & 50 & 0.74 \\
Dysthymia & 56.2 & 58.3 & 1 \\
Suicide attempts & 53.1 & 25.0 & 0.02 \\
Panic disorder & 65.6 & 41.7 & 0.32 \\
Phobias & 59.4 & 33.3 & 0.08 \\
$\quad$ Agoraphobia & 65.6 & 33.3 & 0.49 \\
$\quad$ Social phobia & 50 & 25 & 0.48 \\
$\quad$ Specific phobia & 40.6 & 16.7 & 0.46 \\
Obsessive compulsive disorder & 31.3 & 41.7 & 0.73 \\
Post-traumatic stress disorder & 34.4 & 8.3 & 1 \\
Generalized anxiety & 12.5 & & \\
Substance abuse & 37.5 & 41.7 & - \\
Alcohol abuse & 12.5 & 0 & - \\
Somatoform disorders & 25.0 & 0 & 1 \\
\hline
\end{tabular}

$\mathrm{PP}=$ purgative patients; RP = restrictive patients.

\section{Discussion}

Our study demonstrated that patients with both the restrictive and purgative subtypes of ED showed similar overall impairment and presented deficits in multiple domains of functioning. However, ED patients with the purgative subtype (PP) revealed a more severe degree of impairment in the financial domain.

These results confirm findings of previous studies demonstrating that individuals with ED (including partial forms) show poor psychosocial adjustment ${ }^{8}$ and impairment in a number of domains, including interpersonal relationships, family functions, work, and finance. Furthermore, follow-up studies have shown that impairment in social functioning associated with bulimia nervosa ${ }^{34}$ and anorexia nervosa ${ }^{35}$ may persist even after remission of ED psychopathology and constitutes a significant predictor of mortality. ${ }^{11}$

Patients with restrictive subtypes of ED are known to have a tendency to underestimate the impact of their illness on daily activities and often continue to work and maintain an active lifestyle even at extreme levels of starvation.6,15 Some authors have reported better QoL scores for patients with the restrictive type of anorexia than patients with all other types of ED; the same patients also reported less subjective impairment. Even after controlling for general psychological distress, their scores were similar to those of the general population. ${ }^{13,14,36}$ These findings are not surprising, considering that these patients may perceive weight loss as an improvement in their $\mathrm{QoL}^{6}$ and that often the central purpose of these patients' lives is the maintenance of their emaciated state. ${ }^{13}$ The results of those studies can be explained by the egosyntonic nature of symptoms commonly observed in restrictive subtypes of ED, underscoring the importance of using instruments that objectively assess functioning rather than relying on the patients' reports of subjective feelings. In fact, self-reported instruments and QoL scales may not be reliable in these patients because they may reflect the severity of their psychopathology. In the present study, patients in the RP group scored similar to controls on BSQ, suggesting that patients with restrictive ED were as "satisfied" with their body shape as healthy women. Also, even though our RP reported high levels of restraint food intake upon clinical evaluation, they scored lower on the EAT than expected. In contrast, PP showed higher EAT and BSQ scores, probably because they had a greater awareness of their ED symptoms.

With the application of an objective scale such as the FAST, the restrictive and purgative subtypes of ED displayed similar levels of overall functioning impairment. Impacts on specific areas of functioning, such as autonomy, work, cognition, relationships, and leisure, were very similar between the two subtypes of ED. The PP group showed a more severe impairment in the financial domain, which may be explained by higher levels of impulsivity. Additionally, the PP group showed significant comorbidity with alcohol and drug abuse and more frequently showed a history of suicide attempts.

Consistent with other studies investigating women with ED, ${ }^{37,38}$ most of our ED patients had at least one comorbid psychiatric diagnosis, with anxiety ${ }^{39}$ and affective disorders ${ }^{40}$ being the most common ones. ${ }^{7}$ Our PP and RP groups showed similar rates of comorbidities with major depression, panic disorder, obsessive compulsive disorder, and somatoform disorders.

Considering that ED patients with the purgative subtype tend to have more egodystonic symptoms than restrictive ED patients, the fact that the vast majority 
of individuals enrolled in our treatment program (Adult Eating Disorders Program, HCPA) presented with the purgative subtype of ED may not be due to chance. Furthermore, the fact that there were more inpatients in the RP group may reflect their resistance to seek specific outpatient treatment.

To our knowledge, this is the first study to apply the FAST in individuals with ED. This instrument is a simple, rapid, interviewer-administered scale that assesses functional impairment while focusing on the main difficulties experienced by patients suffering from mental disorders. Studies using the GAF scale have also observed functional impairment in patients with restrictive subtypes of $E D, 7,8$ but GAF scores do not reveal impacts on specific areas of functioning. Higher scores on the FAST and lower scores on the GAF represent higher levels of disability, ${ }^{20}$ and a negative correlation between these scales was also demonstrated in our sample. A potential advantage of the FAST over other measures designed specifically to evaluate impairment in ED patients is the potential to compare their functioning to that of patients with other psychiatric disorders.

The main limitation of our study was the small sample size, particularly in the RP group. Also, the proportion of out- and inpatients differed between the two groups. Moreover, RP and PP groups differed in relation to diagnosis (anorexia nervosa and bulimia nervosa), and some results may reflect this difference. Differences in household income and education level could also be an issue; however, this may be a consequence of better functioning in individuals without psychiatric disorders.

\section{Conclusion}

Our results highlight the importance of evaluating multiple domains of functioning in ED patients using an objective instrument. The findings can be used for targeted treatment planning and to enhance the patients' motivation to change. Our study also suggests that new treatment strategies may be needed to attain better results in functional outcomes in ED patients.

\section{Acknowledgements}

The authors would like to thank Dr. Flavio Kapczinski for his assistance in the project and for revising this manuscript.

\section{References}

1. de la Rie SM, Noordenbos G, van Furth EF. Quality of life and eating disorders. Qual Life Res. 2005;14:1511-22.

2. Bohn K, Doll HA, Cooper Z, O'Connor M, Palmer RL, Fairburn CG. The measurement of impairment due to eating disorder psychopathology. Behav Res Ther. 2008;46:1105-10.

3. Duchesne M, Mattos P, Fontanelle L, Veiga H, Rizo L, Appolinário J. Neuropsychology of eating disorders: a systematic review of the literature. Rev Bras Psiquiatr. 2010;26:107-17.

4. Mond J, Rodgers B, Hay P, Korten A, Owen C, Beumont P. Disability associated with community cases of commonly occurring eating disorders. Aust N Z J Public Health. 2004;28:246-51.

5. Mond JM, Hay PJ. Functional impairment associated with bulimic behaviors in a community sample of men and women. Int J Eat Disord. 2007;40:391-8.

6. Munoz P, Quintana JM, Las HC, Aguirre U, Padierna A, Gonzalez-Torres MA. Assessment of the impact of eating disorders on quality of life using the disease-specific, HealthRelated Quality of Life for Eating Disorders (HeRQoLED) questionnaire. Qual Life Res. 2009;18:1137-46.

7. Striegel-Moore RH, Seeley JR, Lewinsohn PM. Psychosocial adjustment in young adulthood of women who experienced an eating disorder during adolescence. J Am Acad Child Adolesc Psychiatry. 2003;42:587-93.

8. Wentz E, Gillberg C, Gillberg IC, Rastam M. Ten-year followup of adolescent-onset anorexia nervosa: psychiatric disorders and overall functioning scales. J Child Psychol Psychiatry. 2001;42:613-22.

9. Bijl RV, Ravelli A. Current and residual functional disability associated with psychopathology: findings from the Netherlands Mental Health Survey and Incidence Study (NEMESIS). Psychol Med. 2000;30:657-68.

10. Crow SJ, Peterson CB, Swanson SA, Raymond NC, Specker S, Eckert ED, et al. Increased mortality in bulimia nervosa and other eating disorders. Am J Psychiatry. 2009;166:1342-6.

11. Engel K, Wittern $M$, Hentze $M$, Meyer AE. Long-term stability of anorexia nervosa treatments: follow-up study of 218 patients. Psychiatr Dev. 1989;7:395-407.

12. Keel PK, Dorer DJ, Eddy KT, Franko D, Charatan DL, Herzog DB. Predictors of mortality in eating disorders. Arch Gen Psychiatry. 2003;60:179-83.

13. Mond JM, Hay PJ, Rodgers B, Owen C, Beumont PJ. Assessing quality of life in eating disorder patients. Qual Life Res. 2005; 14:171-8.

14. Doll HA, Petersen SE, Stewart-Brown SL. Eating disorders and emotional and physical well-being: associations between student self-reports of eating disorders and quality of life as measured by the SF-36. Qual Life Res. 2005;14:705-17.

15. Hay PJ, Mond J. How to 'count the cost' and measure burden? A review of health-related quality of life in people with eating disorders. J Ment Health. 2010;14:539-52.

16. Development of the World Health Organization WHOQOLBREF quality of life assessment. The WHOQOL Group. Psychol Med. 1998;28:551-8.

17. Brazier JE, Harper R, Jones NM, O'Cathain A, Thomas KJ, Usherwood T, et al. Validating the SF-36 Health Survey Questionnaire: new outcome measure for primary care. BMJ. 1992;305:160-4.

18. Mond JM, Hay PJ, Darby A, Paxton SJ, Quirk F, Buttner $P_{1}$ et al. Women with bulimic eating disorders: when do they receive treatment for an eating problem? J Consult Clin Psychol. 2009;77:835-44.

19. American Psychiatric Association. Diagnostic and statistical manual of mental disorders. 4th ed. Washington: APA; 2010. 
20. Rosa AR, Sanchez-Moreno J, Martinez-Aran A, Salamero $M$, Torrent $C$, Reinares $M$, et al. Validity and reliability of the Functioning Assessment Short Test (FAST) in bipolar disorder. Clin Pract Epidemiol Ment Health. 2007; 3:5.

21. Amorin P. Mini International Neuropsychiatric Interview (MINI): validação de entrevista breve para diagnóstico de transtornos mentais. Rev Bras Psiquiatr. 2000;22:106-15.

22. Garner DM, Olmsted MP, Bohr Y, Garfinkel PE. The Eating Attitudes Test: psychometric features and clinical correlates. Psychol Med. 1982;12:871-8.

23. Nunes MA, Camey S, Olinto MT, Mari JJ. The validity and 4-year test-retest reliability of the Brazilian version of the Eating Attitudes Test-26. Braz J Med Biol Res. 2005;38:1655-62.

24. Cooper PJ, Taylor MJ, Cooper Z, Fairburn CG. The development and validation of the body shape questionnaire. Int J Eat Disord. 1987;6:485-94.

25. Scagliusi FB, Polacow VO, Cordas TA, Coelho D, Alvarenga M, Philippi ST, et al. Psychometric testing and applications of the Body Attitudes Questionnaire translated into Portuguese. Percept Mot Skills. 2005;101:25-41.

26. Nunes MA. Avaliação do impacto de comportamentos alimentares anormais em uma coorte de mulheres [tese]. São Paulo: UNIFESP; 2003.

27. Henderson M, Freeman CP. A self-rating scale for bulimia. The 'BITE'. Br J Psychiatry. 1987;150:18-24.

28. DeRogatis LR, Lipman RS, Covi L. SCL-90: an outpatient psychiatric rating scale--preliminary report. Psychopharmacol Bull. 1973;9:13-28.

29. DeRogatis LR. Symptom Checklist-90-Revised. In: American Psychiatric Association. Handbook of psychiatric measures. Washington: APA; 2000. p. 81-4.

30. Hamilton M. A rating scale for depression. J Neurol Neurosurg Psychiatry. 1960;23:56-62.

31. Aas IM. Global Assessment of Functioning (GAF): properties and frontier of current knowledge. Ann Gen Psychiatry. 2010;9:20

32. Cacilhas AA, Magalhaes PV, Cereser KM, Walz JC, Weyne F, Rosa AR, et al. Validity of a short functioning test (FAST) in Brazilian outpatients with bipolar disorder. Value Health. 2009;12:624-7.
33. Gonzalez-Ortega I, Rosa AR, Alberich S, Barbeito S, Vega $P$, Echeburúa $E$, et al. Validation and use of the functioning assessment short test (FAST) in first psychotic episodes. J Nerv Ment Dis. 2010;198:836-40.

34. Norman DK, Herzog DB. Persistent social maladjustment in bulimia: a 1-year follow-up. Am J Psychiatry. 1984;141:444-6.

35. Sullivan PF, Bulik CM, Fear JL, Pickering A. Outcome of anorexia nervosa: a case-control study. Am J Psychiatry. 1998; 155:939-46.

36. Padierna A, Quintana JM, Arostegui I, Gonzalez N, Horcajo MJ. The health-related quality of life in eating disorders. Qual Life Res. 2000;9:667-74.

37. Garfinkel PE, Lin E, Goering P, Spegg C, Goldbloom DS, Kennedy S, et al. Bulimia nervosa in a Canadian community sample: prevalence and comparison of subgroups. Am J Psychiatry. 1995;152:1052-8.

38. Herzog DB, Nussbaum KM, Marmor AK. Comorbidity and outcome in eating disorders. Psychiatr Clin North Am. 1996;19:843-59.

39. Paes F, Machado $S$, Velasques $B$, Ribeiro $P$, Nardi AE. [Obsessive-compulsive disorder and eating disorders: a continuum or separate diagnoses?]. Rev Bras Psiquiatr. 2011;33:212-3.

40. Seixas C, Miranda-Scippa A, Nery-Fernandes F, AndradeNascimento M, Quarantini LC, Kapczinski F, et al. Prevalence and clinical impact of eating disorders in bipolar patients. Rev Bras Psiquiatr. 2012;34:66-70.

\section{Correspondence}

Carolina Meira Moser

Rua Padre Chagas, 147/1403

90570-080 - Porto Alegre, RS - Brazil

Tel. : +55 (51) 3264.0470

E-mail: cmeiramoser@gmail.com 